\title{
Deep Ocean Passive Acoustic Technologies for Exploration of Ocean and Surface Sea Worlds in the Outer Solar System
}

\author{
By Robert Dziak, Don Banfield, Ralph Lorenz, Haruyoshi Matsumoto, Holger Klinck, \\ Richard Dissly, Christian Meinig, and Brian Kahn
}

\begin{abstract}
Ocean worlds are numerous in our solar system. Here, we present an overview of how passive acoustic monitoring (PAM) and signal detection systems, developed for acoustic sensing in Earth's ocean, might be used to explore an ocean and/or surface sea world in the outer solar system. Three potential seagoing mobile platforms for a PAM system are considered: a saildrone or surface buoy for exploring Saturn's largest moon, Titan, and an autonomous underwater vehicle for exploring the sub-ice oceans of Enceladus, one of Saturn's smaller moons, or Europa, one of Jupiter's larger moons. We also evaluate preparation of an acoustic system and electronics for the rigors of spaceflight and the challenging environments of outer solar system planetary bodies. The relatively benign Europa/Enceladus ocean thermal environment $\left(-40^{\circ}\right.$ to $\left.40^{\circ} \mathrm{C}\right)$ suggests a standard commercial acoustic product may meet system design needs. In comparison, a PAM system for Titan's hydrocarbon seas must function at $-180^{\circ} \mathrm{C}$ temperatures, necessitating testing in liquid nitrogen. We also discuss adapting for outer ocean world exploration, acoustic signal detection, and classification algorithms used widely in ocean research on Earth, as well as data compression methods for interplanetary transmission. The characteristics of geophysical, cryogenic, and meteorological acoustic signals expected in an ocean or surface sea world, including signals from seafloor cold seeps and/or hydrothermal vents, are considered because of their potential to harbor chemosynthetic life.
\end{abstract}

\section{INTRODUCTION}

Spacecraft exploration of the outer solar system over the last three decades has led to the discovery of several planetary bodies that likely have liquid water oceans beneath a shell of ice that covers the planetary surface (Nimmo and Pappalardo, 2016; Lunine, 2017). For example, Jupiter's moon Europa has a relatively thin $(<10 \mathrm{~km})$ icy shell that exhibits a variety of tectonic features, and Saturn's small but geologically active moon Enceladus also has a global ocean. Enceladus's ocean is relatively deep beneath the planetary surface, but surface fractures at the south pole allow ice and gas from the ocean to escape into space (Lunine, 2017). Saturn's moon Titan is the only planetary body with an atmosphere and liquid hydrocarbon seas and lakes (Stofan et al., 2007).
In situ exploration of these outer solar system ocean and surface sea worlds might benefit from technologies and techniques that oceanographers have developed to explore Earth's ocean. Earthfocused oceanographers may also benefit from exploration of other ocean worlds because it will further our understanding of ocean creation, dynamics, and the development of hydrologic cycles on these planetary bodies, and provide insight into similar systems on Earth. Moreover, the dynamics of global oceans beneath tidally flexing ice shells represents a rich set of problems that have barely begun to be explored (Nimmo and Pappalardo, 2016) and may provide insights into the dynamics of ice caps and ice sheets in Earth's polar regions. Continued exploration of ocean and surface sea worlds is criti- cal for one of the most compelling reasons of all: these ocean worlds could harbor life. Ocean worlds have the necessary combination of factors (liquid water, heat energy, chemical nutrients) that can lead to the development of life as we know it on Earth (Nimmo and Pappalardo, 2016). Indeed, it is recognized that these ocean worlds likely have developed analogs to Earth's deep-ocean hydrothermal systems (Vance et al., 2007). On Earth, in the absence of sunlight and hence photosynthesis, chemosynthetic organisms use the various chemicals coming out of hydrothermal vents to create energy. Chemosynthesis generally requires a redox gradient but not necessarily with oxygen (Chyba and Phillips, 2001), implying chemosynthetic life could have developed on other planets without the presence of oxygen.

In this study, we consider how hydrophone and passive acoustic recording technology developed for use in Earth's ocean might be applied to ocean research in the outer solar system. As for potential vehicles, or seagoing platforms, we consider a saildrone/submarine for Titan and a submarine for exploration of the subsurface oceans of Europa or Enceladus (Figures 1 and 2). For example, the saildrone may mirror similar designs used on Earth (Figure S1). A range of possible mission architectures already considered for exploring Titan's seas include (1) a capsule serving as a free-drifting buoy (Stofan et al., 2013; Lorenz and Mann, 2015), (2) propelled surface vessels (i.e., boats; Lorenz et al., 2018), and (3) submersibles with buoyancy control 


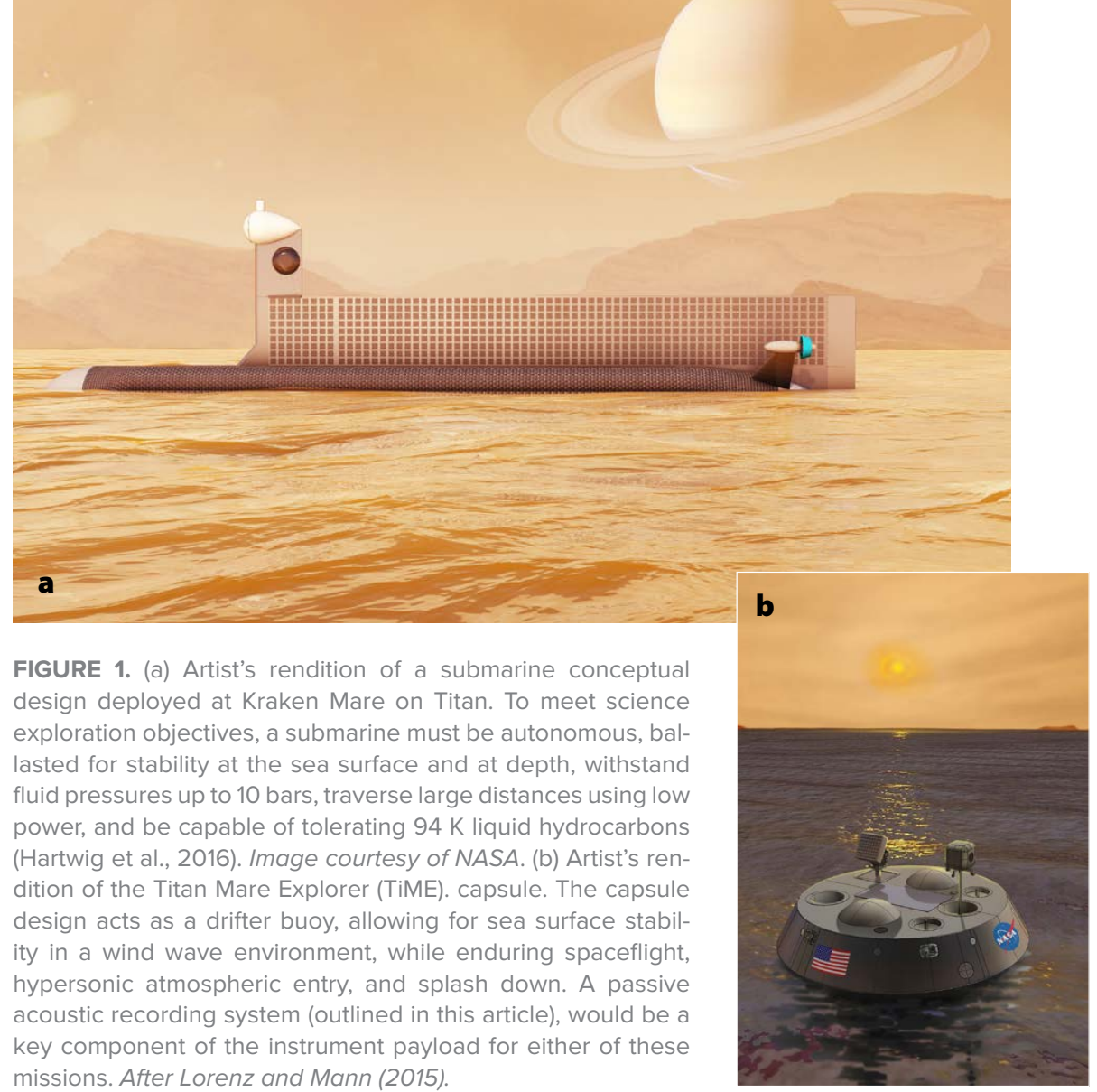

FIGURE 2. Artist's conception of one possible autonomous underwater vehicle (AUV) system approaching a volcanic vent in Europa's ocean. A passive acoustic hydrophone system would be a critical instrument for such an outer world probe not only for finding sub-ice volcanic centers and seafloor hydrothermal systems but also for determining spatial distribution of volcanic centers and their seismo-acoustic activity levels prior to direct sampling. Image courtesy of NASA Jet Propulsion Laboratory (https://www.jpl.nasa.gov/spaceimages/)
(Hartwig et al., 2016). We also briefly discuss preparation of the hydrophone technology for the rigors of spaceflight, the challenging outer solar system environments, and the required planetary protection considerations. We present an overview of instrument back-end electronics and signal classification algorithms for efficient use of the limited downlink bandwidth expected from exploration vehicles. Acoustic signals from seafloor hydrothermal vents are of particular scientific interest because of the vents' potential to harbor extant life. Thus, passive acoustic techniques may be uniquely poised to detect these astrobiologically relevant phenomena.

\section{CHARACTERISTICS OF OUTER SOLAR SYSTEM OCEANS AND SEAS}

Table 1 lists several of the essential physical characteristics of Europa, Enceladus, and Titan, the three outer solar system bodies that are the focus of proposed/ planned exploration missions. All three of these planetary satellites have thin atmospheres and low atmospheric pressure (relative to Earth) as well as very low surface temperatures that enable the formation of a thick ice shell on the planetary surface. Internal heating driven by gravity-induced tidal stresses suggests that these worlds also harbor deep oceans beneath their surface ice shells; however, because the oceans are hidden, their thicknesses and compositions are not well known (e.g., Iess et al., 2012). For Europa, the inferred moment of inertia and presumption that the icy shell is not more than a few tens of kilometers thick implies an ocean thickness of $<150 \mathrm{~km}$ (Schubert et al., 2004). The Galileo spacecraft survey indicated Europa's sub-ice ocean is composed of a water-brine mixture, with magnesium sulfate salt (McCord and Hansen, 1998). On Enceladus, the ocean is perhaps $10 \mathrm{~km}$ thick on average but greater at the south pole, reaching depths of $<30 \mathrm{~km}$ (e.g., Cadek et al., 2016). The Cassini mission sampled the geyser plumes at Enceladus that originate from its sub-ice ocean and found the plumes to be composed of water vapor with a mix- ture of salts and ice particles (Postberg et al., 2018). Because pure water has very low conductivity, dissolved ions must be present at some level in the oceans of Jupiter's larger icy moons, where induction signals have been detected.

The evolution models for Titan suggest a $<400 \mathrm{~km}$ thick water-ammonia ocean beneath a $<100 \mathrm{~km}$ ice shell (e.g., Vance et al., 2017). Compared with Earth, satellite sub-ice oceans are not only poorly characterized but are also driven by a different set of forces. On Earth, wind stresses and salinity variations play a major role in ocean dynamics (e.g., Schmitz and McCartney, 1993); for ice-covered satellite oceans, wind stresses are certainly negligible, and salinity's role is uncertain (see below).

Titan also hosts a methane-based hydrologic cycle that supports standing bodies of liquid hydrocarbons on the planetary surface. Observations from Cassini have revealed more than 650 lakes and seas scattered throughout the north and south polar regions (Hayes, 2016). Cassini surveys also revealed that the 
depths of Titan's seas and lakes can exceed $100 \mathrm{~m}$ (e.g., Mastrogiuseppe et al., 2019). It is thought the seas are composed of ethane, with $\sim 10 \%$ methane and smaller amounts of dissolved nitrogen and propane (e.g., Cordier et al., 2009). Kraken Mare and Ontario Lacus, the largest seas in the south, may have a similar composition. In contrast, comparison of the small observed radar attenuation with laboratory data suggests that the northernmost seas, Ligeia and Punga Mare, are almost pure liquid methane (e.g. Mastrogiuseppe et al., 2019). Indeed, there may be a compositional variation across the linked Ligeia/ Kraken system that is similar to the Black Sea/Mediterranean Sea gradient, forced by methane precipitation with involatile ethane analogous to salt in Earth's ocean (Lorenz, 2014). In addition to the fundamental differences in physical properties of hydrocarbons compared to water, a notable peculiarity of Earth's ocean and lakes is that at freezing temperatures, terrestrial bodies of liquid become stably stratified by density, causing sound speed to increase with depth. This does not happen on Titan, nor does ice form at the sea surface. Because the solid phase of hydrocarbons is denser than the liquid phase, if freezing should occur, the solids will generally sink to the seafloor.

Arvelo and Lorenz (2013) modeled temperature, density, sound speed, and sound absorption for Titan's seas (Figure S2) and found that even with

TABLE 1. Essential physical characteristics for Europa, Enceladus, and Titan.

\begin{tabular}{|c|c|c|c|}
\hline & EUROPA & ENCELADUS & TITAN \\
\hline $\begin{array}{l}\text { ICE SHELL } \\
\text { THICKNESS }\end{array}$ & $15-25 \mathrm{~km}^{\mathrm{a}}$ & $\begin{array}{c}30-40 \mathrm{~km} ; \\
<10 \mathrm{~km} \text { at poles }\end{array}$ & $<200 \mathrm{~km}^{\mathrm{c}}$ \\
\hline $\begin{array}{r}\text { OCEAN/SEA } \\
\text { DEPTH }\end{array}$ & Ocean: 60-150 km d & Ocean: $26-31$ km ${ }^{\mathrm{e}}$ & $\begin{array}{l}\text { Sub-lce Ocean: }<400 \mathrm{~km}^{\mathrm{f}} \\
\text { Seas and Lakes: } 2.9-160 \mathrm{~m}^{\mathrm{g}, \mathrm{h}}\end{array}$ \\
\hline $\begin{array}{r}\text { OCEAN/SEA } \\
\text { COMPOSITION }\end{array}$ & $\begin{array}{l}\text { Water-Brine: } \\
-40^{\circ} \mathrm{C} \text { to } 40^{\circ} \mathrm{C}^{\mathrm{i}} \\
\text { (for example, } \\
\text { magnesium sulfate } \\
\left(\mathrm{MgSO}_{4}\right) \text {, sulfuric } \\
\text { acid hydrate } \\
\left.\left(\mathrm{H}_{4} \mathrm{O}_{5} \mathrm{~S}\right)\right)^{\mathrm{j}}\end{array}$ & $\begin{array}{l}\text { Water with Salts } \\
\left(-\mathrm{Na},-\mathrm{Cl},-\mathrm{CO}_{3}\right)\end{array}$ & $\begin{array}{c}\text { Sub-Ice Ocean: } \\
\text { water/ammoniak } \\
\text { Surface Lakes and Seas: } \\
\sim 79 \% \text { ethane }\left(\mathrm{C}_{2} \mathrm{H}_{6}\right), \\
\sim 8 \% \text { propane }\left(\mathrm{C}_{3} \mathrm{H}_{8}\right), \\
\sim 10 \% \text { methane }\left(\mathrm{CH}_{4}\right), \\
\sim 3 \% \text { hydrogen cyanide }(\mathrm{HCN}), \\
\sim 1 \% \text { butane, acetylene }\end{array}$ \\
\hline $\begin{array}{r}\text { SURFACE } \\
\text { TEMPERATURE }\end{array}$ & $\begin{array}{l}\text { Equator: }-160^{\circ} \mathrm{C} \\
\text { Poles: }-220^{\circ} \mathrm{C}\end{array}$ & $\begin{array}{l}\text { Equator: }-128^{\circ} \mathrm{C} \\
\text { Poles: }-240^{\circ} \mathrm{C}\end{array}$ & Equator: $-179.5^{\circ} \mathrm{C}^{\mathrm{m}}$ \\
\hline $\begin{array}{r}\text { ATMOSPHERIC } \\
\text { SURFACE } \\
\text { PRESSURE }\end{array}$ & $10-12$ bars $^{n}$ & Variable (Plumes) ${ }^{\circ}$ & 1.47 bars \\
\hline $\begin{array}{l}\text { ATMOSPHERIC } \\
\text { COMPOSITION }\end{array}$ & $\mathrm{O}_{2}$ & $\begin{array}{c}91 \% \text { water vapor, } \\
4 \% \mathrm{~N}, \\
3.2 \% \mathrm{CO}_{2} \\
1.7 \% \mathrm{CH}_{4}\end{array}$ & $\begin{array}{c}95 \%-98 \% \mathrm{~N}_{2} \\
1.4 \%-4.9 \% \mathrm{CH}_{4} \\
0.2 \% \mathrm{H}_{2}^{\mathrm{p}}\end{array}$ \\
\hline $\begin{array}{r}\text { PROPORTION } \\
\text { TO EARTH } \\
\text { DIAMETER } q\end{array}$ & $25 \%$ & $4 \%$ & $40.4 \%$ \\
\hline $\begin{array}{l}\text { SURFACE } \\
\text { GRAVITY }\end{array}$ & $1.314 \mathrm{~m} \mathrm{~s}^{-2}$ & $0.113 \mathrm{~m} \mathrm{~s}^{-2}$ & $0.138 \mathrm{~m} \mathrm{~s}^{-2}$ \\
\hline $\begin{array}{l}\text { DISTANCE } \\
\text { FROM SUN }\end{array}$ & $7.8 \times 10^{8} \mathrm{~km}$ & $1.4 \times 10^{9} \mathrm{~km}$ & $1.2 \times 10^{9} \mathrm{~km}$ \\
\hline $\begin{array}{l}\text { TRAVEL TIME } \\
\text { FROM EARTH }\end{array}$ & 6 years & $2.3-6$ years $^{r}$ & $2.3-6$ years $^{r}$ \\
\hline \multicolumn{3}{|l|}{ a Nimmo et al. (2003) } & m Mitri et al. (2007) \\
\hline \multicolumn{2}{|l|}{ b Cadek et al. (2016) } & $\begin{array}{l}\text { giuseppe et al. (2014) } \\
(2016)\end{array}$ & n McGrath (2009) \\
\hline \multicolumn{2}{|c|}{ c Hemingway et al. (2013) } & $\begin{array}{l}\text { et al. }(2004) \\
\text { etb) }\end{array}$ & ○ Dougherty et al. (2006) \\
\hline \multicolumn{2}{|c|}{ d Pappalardo et al. (1999) } & $\begin{array}{l}\text { et al. (2004) } \\
\text { det al. (1998) }\end{array}$ & p Niemann et al. (2005) \\
\hline \multicolumn{2}{|l|}{ e Choblet et al. (2017) } & \multirow{2}{*}{$\begin{array}{l}\text { al. (2012) } \\
\text { et al. (2009) }\end{array}$} & q https://ssd.jpl.nasa.gov/ \\
\hline \multicolumn{2}{|l|}{${ }^{f}$ Vance et al. (2017) } & & ?sat_phys_par \\
\hline
\end{tabular}

off-the-shelf piezoelectric sonar transducers, a relatively simple sonar system should generate sufficient acoustic power to enable good sound propagation and enable sensing of the environment in a $1 \mathrm{~km}$ deep cryogenic hydrocarbon sea. In Titan's low gravity $\left(1.35 \mathrm{~m} \mathrm{~s}^{-2}\right)$, the pressure variation with depth in the sea is an order of magnitude weaker than that of Earth. Thus, while atmospheric pressure at sea level is higher on Titan (1.49 bar) than on Earth, at $1 \mathrm{~km}$ depth, the pressure is $\sim 11.5$ bars on Titan as compared to 101 bars on Earth. Sound speeds in methane and ethane are $1,498.2 \mathrm{~m} \mathrm{~s}^{-1}$ and $1,971.0 \mathrm{~m} \mathrm{~s}^{-1}$, respectively, at $95 \mathrm{~K}$ (https://webbook.nist.gov/). Figure S2 shows an example temperature, density, and sound speed profile for Titan. Note that the vertical extent of a $1 \mathrm{~km}$ hydrocarbon sea is small enough compared with Titan's radius $(2,575 \mathrm{~km})$ that gravity $g$ can be considered constant with depth, in contrast to the deeper $(\sim 100 \mathrm{~km})$ liquid water oceans of icy satellites like Europa, where $g$ varies appreciably with depth (Leighton et al., 2013). Arvelo and Lorenz (2013) estimate acoustic signal loss due to sound absorption $\alpha$ in Titan's methane seas is expected to be very low $\left(\sim 0.035 \mathrm{~dB} \mathrm{~km}^{-1}\right.$ measured at $20 \mathrm{kHz}$ ) and likely to have little effect on sound propagation.

\section{OCEAN WORLD GEOPHYSICAL SIGNALS RECORDED ON A HYDROPHONE}

On an ocean world, whether ice-covered or open, acoustic waves propagating through water or ice provide a very effective means for detecting and evaluating mega-sources of fracturing and volcanism on a planetary scale, thus giving an "over-the-horizon" sense of the world that is not available at a single landing site (Lee et al., 2003; Leighton et al., 2013). A variety of environmental acoustic signal sources can be expected in an ocean world. These sources should be similar to those common on Earth and include fracturing of cryo- and/or lithic-crust 
(quakes), explosive volcanism, debris flows/landslides, meteor impacts, and buoyant hydrothermal fluid plumes. Moreover, as is the case on Titan where there are open fluid lakes or seas, meteorological sound sources from precipitation, surface wave breaking, waterfalls, and wind-wave interaction can also be expected (Arvelo and Lorenz, 2013). Thus, the unique scientific contribution achieved by using hydrophones and hydroacoustic signal detection techniques on Earth is likely to be the same for other ocean worlds. Hydrophones are relatively inexpensive to build, and the low acoustic wave attenuation characteristics in the ocean permit hydrophones to detect much weaker acoustic signals originating from geophysical phenomena than can be detected by seismometers on the planetary surface (Dziak et al., 2015).

In our experience, it is not uncommon to detect acoustic signals (broadband and single tone) that are not easily classified. This issue raises an important question: given the expected uncertainty in interpreting sound signals and sources occurring in the waters of an outer ocean world, how useful will omnidirectional passive acoustics be? The ocean science community's long experience in identifying the wide variety of underwater sound sources recorded by hydrophones on Earth suggests this problem is manageable. In the past several decades, great strides have been made by the ocean acoustics community in identifying the unique signal characteristics of vocal marine animals using single omnidirectional hydrophones on moorings and mobile platforms (e.g., Baumgartner et al., 2019; Au et al., 2000). This is also true for geophysical sounds, and we think it will be possible to identify natural sound sources where there are clear analogs on Earth.

\section{Cryogenic Seismo-Acoustic Sources}

For ocean worlds with ice shells, we expect to record two basic types of cryogenic sources on a sub-ice hydrophone that should be similar to signals recorded in Earth's polar oceans. The first is "icequakes," where fracturing of large sections (meters to kilometers) of ice generate strong seismo-acoustic waves (Figure 3a,b; Dziak et al., 2015). The second is ice tremors, the harmonic signals produced when large blocks (several kilometers long) of ice impact one another, remain in contact, then slide in stickslip fashion past each other (Figure 3c; MacAyeal et al., 2008).

There are a number of potential source mechanisms for seismo-acoustic signals generated by the breakup of sea surface ice on Earth. Podolskiy and Walter (2016) provide an extensive review of this literature. To summarize, possible source mechanisms include rifting, nearsurface crevassing, stick-slip motion/ rupture of an ice-bedrock interface, collision and sliding between two adjacent ice masses, and sea surface ice sheet flexures
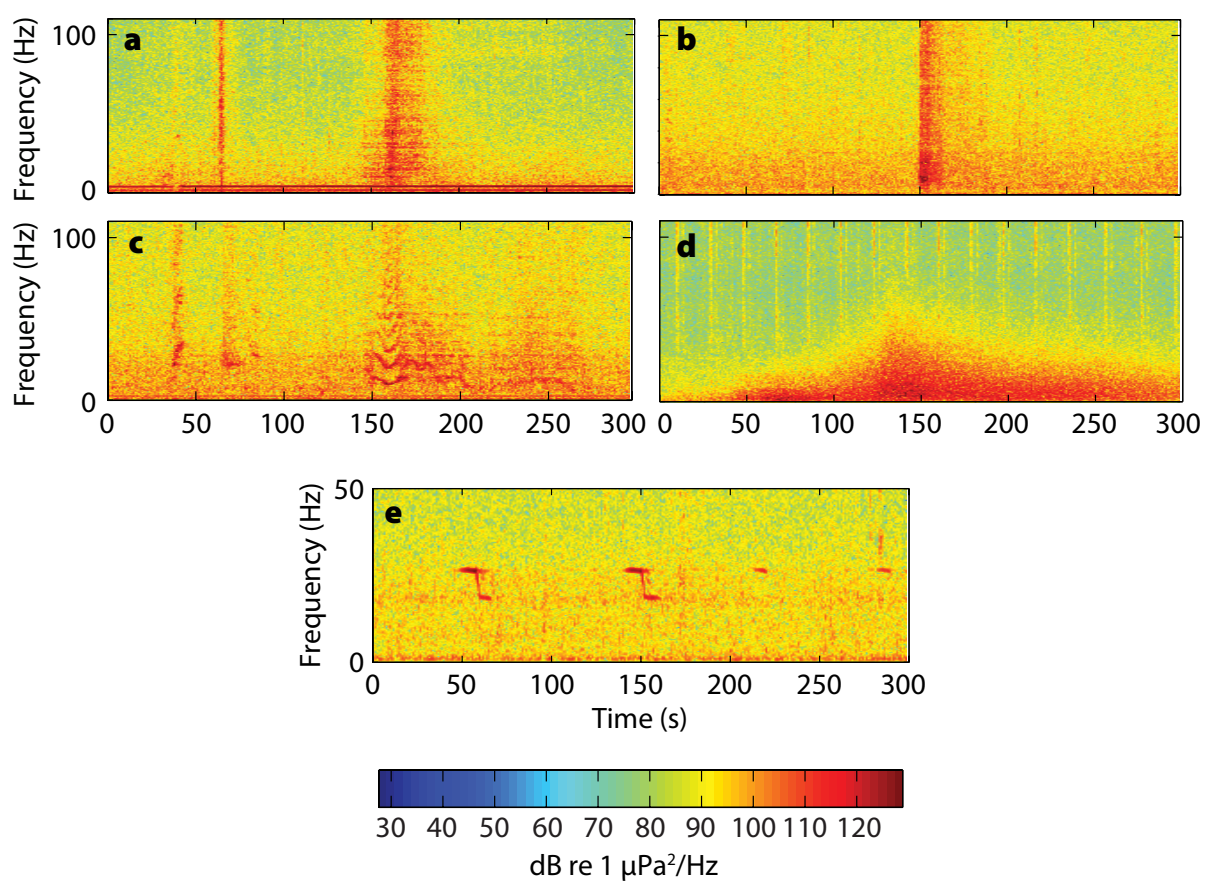

FIGURE 3. Frequency-time displays (spectrograms) of various sound sources recorded in the Southern Ocean near the Antarctic Peninsula ( $900 \mathrm{~m}$ depth). The sound energy level is roughly equivalent for all sources; however, each varies in prevalence through the year. (a) A record of an emergent (i.e., the signal is spread out in time), broadband icequake acoustic arrival caused by fracturing of sea ice or a nearby iceberg. (b) A record of an impulsive, short-duration icequake signal indicating that the icequake may be closer to the recorder, exhibiting less attenuation than the emergent record shown in (a). (c) A record showing fundamental and harmonic overtones of an iceberg harmonic tremor caused by grounding and scraping of an iceberg keel along the seafloor (MacAyeal et al., 2008). (d) A record showing emergent, long-duration seismo-acoustic energy $(<50 \mathrm{~Hz})$ from a nearby earthquake (body wave magnitude $\sim 4)$. An example of anthropogenic signals from a nearby seismic survey ship can also be seen as broadband signals repeating every 30 seconds in the background. (e) A recording showing a bioacoustic signal from an Antarctic blue whale. Antarctic blue whale vocalizations are identifiable as a series of band-limited, down-swept frequency tones from $28 \mathrm{~Hz}$ to $22 \mathrm{~Hz}$. After Dziak et al. (2015) 
and Pappalardo, 2008; Vance et al., 2018). Thus, the ice shells on Europa and Enceladus will very likely produce icequakes with a wide range of magnitudes (acoustic source levels). The magnitude range of icequakes will likely follow a power-law distribution in number and size as quakes do on Earth (Panning et al., 2006), which will allow assessment of the dynamics of ice shell movement and breakup in response to tidal forcing. It may also be possible to use icequakes to detect the explosions of water vapor through the ice shell observed on Enceladus. The cryo-volcanic and water plume systems on Enceladus are thought to exhibit similar geometries and acoustic sources as Earth's hydrothermal geyser systems, with volatile flow through a conduit system producing cavitation and chamber resonance (Vance et al., 2018). Tidal fracturing of the ice shell will also likely generate substantial ice tremor signals. The magnitude and frequency bands of ice tremors are directly proportional to the sizes of the ice blocks (or plates) that impact one another. Thus, monitoring tremors will provide insights into the dynamics of ice shell breakup. On Earth, large icebergs can generate ice tremors as they impact and grind against the shallow seafloor (Dziak et al., 2015). We do not anticipate the oceans on Europa or Enceladus will be shal-

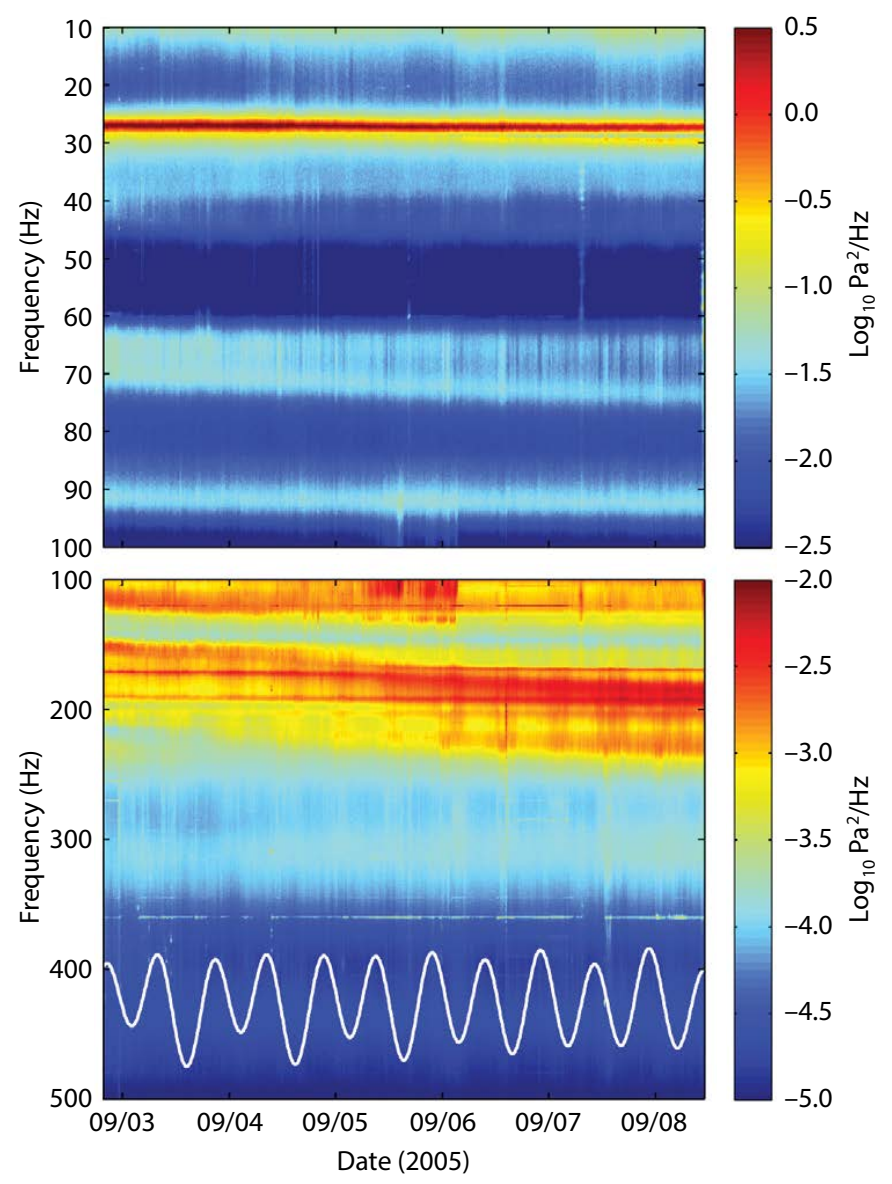

FIGURE 4. Spectrogram of the temporal evolution of the acoustic power spectrum of a "black smoker" hydrothermal vent. The narrowband tones at $25 \mathrm{~Hz}, \sim 100 \mathrm{~Hz}$, and $\sim 200 \mathrm{~Hz}$ are from the vent source. The white lines at the bottom show the tidal phase, indicating tides modulate this vent's acoustic signature at $200 \mathrm{~Hz}$. After Crone et al. (2006) low enough for their ice shells to impact their sub-ocean lithic crusts. Interestingly, in contrast to the polar regions on Earth, seismic noise due to thermal expansion/contraction of the ice shells is not likely to be substantial due to the great distances of Europa and Enceladus from the sun, resulting in smaller diurnal and seasonal temperature variations (Vance et al., 2018).

\section{Geophysical Seismo-Acoustic and \\ Meteorological Sources}

We expect to detect four main types of geophysical acoustic sources generated from ocean lithic floor on ocean worlds. We assume these geophysical signals occur in or near the subocean lithic crust and include quakes due to crustal fracturing (e.g., Figure 3d), volcanic (harmonic) tremor caused by magma flowing in the shallow crust, explosions from violent degassing of lava erupting on the ocean floor (e.g., Caplan-Auerbach et al., 2017), and resonant and broadband noise associated with hydrothermal fluid vents (Figure 4). Volcanic eruptions on Earth are typically associated with substantial amounts of earthquake activity (e.g., Klein et al., 1987), but volcanic earthquakes tend to be much smaller in magnitude than events produced by large plate boundary faults. Thus, these two types of quakes should be distinguishable on an ocean world. Moreover, meteorite impacts, both on an open sea surface and on lithic/ice crust, should also be sources of detectable seismo-acoustic waves, as their high-velocity collisions can cause massive fracturing and generate significant pressure-wave energy.

When magma erupts on the seafloor on Earth or flows through a lithic crust, it can also produce very distinctive resonant tremor signals (e.g., Dziak et al., 2012). Volcanic tremor acoustic signals are similar to those of ice tremor, exhibiting both fundamental and multiple overtones (e.g., Figure 3c) but typically lower frequencies $(<20 \mathrm{~Hz})$. Volcanic tremor also tends to be very low amplitude and attenuates rapidly, necessitating the employment of hydroacoustic detection methods to record these signals at tens of kilometers and over-the-horizon distances. Additionally, it would seem that an under-ice hydrophone would have a better chance of detecting the relatively low-amplitude seismic/tremor signals from sub-ocean volcanic sources than seismometers on the outer surface of a planetary ice shell. The upward-propagating ocean acoustic phases would scatter when they encountered the ocean ice-shell interface (Keenan and Merriam, 1991), and attenuation would increase as the signals propagated through the thick, icy crust.

If we can detect volcanic explosions and seismic and/or tremor events, we may be able to use these signals to localize volcanic centers (i.e., large areas of magmatic activity on the sub-ocean floor). On Earth, seafloor volcanic centers can host vigorous high-temperature $\left(>200^{\circ}-300^{\circ} \mathrm{C}\right)$ fluid vents. Water, heated by subsurface magma bodies, exits the seafloor through fractures, building polymetallic sulfide chimneys as the metals precipitate from the super-heated fluid upon contact with the 
near-freezing seawater. The fluid flowing through these chimneys can be turbulent, producing seismo-acoustic harmonic tones (tremor) through resonance of the chimney conduit and oscillations at the chimney nozzle (Figure 4). Although the amplitude of these signals is not expected to be large (e.g., Crone et al., 2006), because of the astrobiological significance of these chimneys, they are the most interesting sources to use to establish the sensitivity of our instruments (see Table 2). Detection ranges of $\sim 1 \mathrm{~km}$ are possible on Earth in the $5-500 \mathrm{~Hz}$ band (Crone et al., 2006) despite high ambient noise from ship traffic and microseisms.

On the outer ocean worlds, we might expect hydrothermal vent detectability at much farther distances, depending on the actual ambient noise characteristics. Titan is the only satellite in the solar system with a dense atmosphere and hydrocarbon seas. Its undersea noise is expected to be dominated by molecular agitation, sea surface dynamics, and occasional precipitation. The sea surface noise should vary with wind speed, due to the entrainment and ringing of bubbles by sea surface wave breakers. Surface wind on Titan has been shown to be $\leq 2 \mathrm{~m} \mathrm{~s}^{-1}$, which may generate waves up to $\sim 1 \mathrm{~m}$ high (Lorenz et al., 2012). Estimates are that wind speed and wave height would produce $40 \mathrm{~dB}$ re $1 \mu \mathrm{Pa}^{2} / \mathrm{Hz}$ of noise at $20 \mathrm{kHz}$ in Titan's seas, but it is also likely this noise will be broadband in the tens of hertz to kilohertz range as it is on Earth (Arvelo and Lorenz, 2013). Sound can also be generated by precipitation (e.g., Ma and Nystuen, 2005), which is a possibility for Ligeia Mare. Arvelo and Lorenz (2013) suggest rainfall is likely to occur at rates of tens of millimeters per hour. This rainfall would be methane, and its impact on the sea surface would produce broadband sounds (tens of hertz to kilohertz). Thus, we anticipate using an undersea hydrophone to record time variation in rainfall and wind-wave noise on the sea surface to provide insights into Titan's weather dynamics and climate conditions. Moreover, because Kraken
Mare is composed of two basins separated by a narrow ( $\sim 17 \mathrm{~km}$ wide) strait, it is thought that current velocity in this strait may be high $\left(\sim 0.5 \mathrm{~m} \mathrm{~s}^{-1}\right)$. Acoustic flow noise could also be a significant source of ambient sound in these methane/ethane seas (Lorenz., 2014).

Bubble streams emanating from cold seeps and hydrothermal systems on the ocean floor are other potential sources of ambient sound in the Titan seas. Methane seep bubble streams are a fairly common feature on Earth's shallow (50-1,725 m) continental shelves (Johnson et al., 2015). These bubble streams produce a series of broadband $(0.5-4.5 \mathrm{kHz})$ acoustic pulses of short duration $(\sim 0.2-0.5 \mathrm{msec})$ that occur in clusters of pulses that last two to three seconds (e.g., Figure S5; Dziak et al., 2018). The bubble streams generate sound during bubble formation; detachment of the gas bubble from the end of a tube or conduit causes the bubble to oscillate, producing sound (Leifer and Tang, 2007). Titan may also be cryovolcanically active (e.g., Lopes et al., 2013), and it is possible that some form of thermal-fluid vents may also exist on the bottoms of Titan's seas, similar to systems discussed for the lithic seafloors of Europa and Enceladus. Indeed, Cassini radar showed evidence of ephemeral "bright features" at the surface of Ligeia Mare, interpreted as rising gas bubbles (Hofgartner et al., 2014). Modeling of thermodynamic instabilities indicates $\mathrm{N}_{2}$ can be exsolved in the Titan seas, producing streams of centimetersized bubbles (Cordier et al., 2017). Thus, seismic and tremor signals from cryo-volcanic activity, as well as the harmonic tones from fluid flow at hydrothermal vents, are all potential sources of sound in Titan's seas. Lastly, as both cold and hot vents are sources of chemosynthetic life on Earth, and if found on Titan, they may also host extant life.

\section{Biological Acoustic Signals}

We think the most likely places for life to thrive on ocean-ice worlds like Europa and Enceladus are thermal hot springs associated with ocean-floor volcanic centers or, as may be the case for Titan, cold seeps in the shallow seas. As on Earth, the hot springs and cold seeps provide the energy source for chemosynthetic ecosystems to develop and thrive. These vent ecosystems can exhibit a diverse range of biota (e.g., microbes, tube worms, mussels, shrimp, and crabs). Thus, one method to find life would be to detect and locate these volcanic centers/hotsprings and/or cold seeps using the geophysical acoustic signals they produce, then directly sample these chemosynthetic environments to search for chemical evidence of life (e.g., Figure 2).

The majority of marine vertebrates on Earth has evolved to use sound to navigate, orient, and find food (Au et al., 2000). Large baleen whales (e.g., blue, fin, and right) exhibit vocal ranges from $10 \mathrm{~Hz}$ to $1 \mathrm{kHz}$ (e.g., Figure 3e). Toothed whales, dolphins, porpoises, and pinnipeds vocalize and echolocate in the tens of hertz to hundreds of kilohertz range, while vocal fish species (e.g., cod, pollack, salmon, herring) can produce sounds ranging from $20 \mathrm{~Hz}$ to as high as $8 \mathrm{kHz}$ (Web et al., 2008). Even animals as small as snapping shrimp are capable of producing source levels in excess of $190 \mathrm{~dB} 1 \mu \mathrm{Pa}$ at $1 \mathrm{~m}$ (in the $5-20 \mathrm{kHz}$ band) by collapsing a cavitation bubble when clos-
TABLE 2. Notional requirements for hydrophone.

\begin{tabular}{|c|c|c|c|}
\hline & & $\begin{array}{c}\text { EUROPA/ } \\
\text { ENCELADUS }\end{array}$ & TITAN \\
\hline \multirow{6}{*}{ 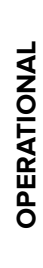 } & Temperature & $-40^{\circ} \mathrm{C}$ to $40^{\circ} \mathrm{C}$ & $-230^{\circ} \mathrm{C}$ to $40^{\circ} \mathrm{C}$ \\
\hline & Static Pressure & $1-1,300$ bars & $1-10$ bars \\
\hline & Acidity & $3-8 \mathrm{pH}$ & N/A \\
\hline & Sensitivity Floor & $-200 \mathrm{~dB} V / \mathrm{uPa}$ & $-200 \mathrm{~dB} V / \mathrm{uPa}$ \\
\hline & Saturation & $150 \mathrm{~dB}$ & $150 \mathrm{~dB}$ \\
\hline & Bandwidth & $0.01-40 \mathrm{kHz}$ & $0.01-40 \mathrm{kHz}$ \\
\hline \multirow{5}{*}{ 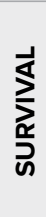 } & Temperature & $-50^{\circ} \mathrm{C}$ to $150^{\circ} \mathrm{C}$ & $-196^{\circ} \mathrm{C}$ to $50^{\circ} \mathrm{C}$ \\
\hline & Pressure & $0-1,300$ bars & $0-20$ bars \\
\hline & Radiation (TID) & $200 \mathrm{krad}$ & $20 \mathrm{krad}$ \\
\hline & Outgassing & TBD & TBD \\
\hline & Acceleration & $25 \mathrm{~g}$ & $25 \mathrm{~g}$ \\
\hline
\end{tabular}


ing their larger claws (Bohnenstiehl et al., 2016). Snapping shrimp use this sound to stun their prey (typically small fish). It thus seems plausible that if life exists and thrives in these ocean worlds, even very simple creatures may have developed an acoustic-based means to sense and interact with their surroundings. We don't know the exact character and frequency band these biotic sounds may take, but if they are higher amplitude than ambient background noise levels, they can be detected, categorized, and quantified.

\section{INCLUSION OF PAM SYSTEMS ON OCEAN WORLD EXPLORATION VEHICLES}

The hydrophone system described in this article could be used for a near-term mission that inserts a vehicle into a Titan sea (e.g., Figure 1). One option would be to mount the hydrophone to the hull of a saildrone or submarine. We know from saildrone deployments on Earth that hull-mounted acoustic systems are subjected to large hull vibrations associated with vehicle movement across the sea surface. A better option would be to position the hydrophone on a tether, or possibly use a winch system to deploy an array of hydrophones some distance from the vehicle's hull, while the electronics would remain inside and thermally controlled. A recent study of flow noise on ocean gliders demonstrated that lower vehicle speeds $\left(<25 \mathrm{~cm} \mathrm{~s}^{-1}\right)$ result in lower ambient noise levels in the $50-200 \mathrm{~Hz}$ band, to the point where ambient noise levels were comparable to fixed acoustic recorders (Fregosi et al., 2020). In contrast, increased vehicle speeds will increase flow noise energy. Thus, recording relatively high-energy geophysical or cryogenic sound sources may be possible from a surface vehicle, while seafloor bubble streams will likely be difficult to detect, given their low expected source levels. Bubble detection may only be possible with relatively low vehicle speed, low ambient sound conditions, and proximity to the bubble source.

The hydrophone could also be a can- didate for an initial Europa lander mission (staying on the frozen surface) or a follow-on mission to Europa or Enceladus that would endeavor to enter a fluid sea, either via cracks in the surface ice or melting through the ice shell (e.g., Figure 2). This ocean worlds hydrophone system may potentially enable detection and monitoring of geophysical acoustic sources occurring within and at the boundaries of the oceans and seas on these moons. On Earth, underwater sound (especially low frequency) propagates very efficiently in dense media such as seawater, where acoustic signatures associated with geophysical events, meteorological events (e.g., high winds and waves caused by storms), or biological sources (e.g., infrasonic baleen whales calls) are often detectable at distances of tens to hundreds of kilometers (e.g., Dziak et al., 2015). Thus, acoustic sensing might also be an effective exploration tool within the exotic ocean worlds of the solar system. The acoustic recording system would need to be broadband enough to enable detection and identification of acoustic signals from a wide range of sources from these outer worlds and capable of parameterization of the signals for transmission back to Earth.

In the following sections, we consider development of a passive acoustic recording module that might feasibly be included on a future mission to Europa, Enceladus, or Titan. The instrument design seeks to minimize its resource footprint to roughly match that available for realistic mission scenarios. An autonomous signal processing capability would be built in as well to reduce the volume of acoustic data for transmission back to Earth. To assess the feasibility of including a passive acoustic system on a future ocean worlds exploration mission, we have taken the baseline Europa Lander resource budget to estimate instrument design limitations. Detailed payload and power considerations, as well as the use of outer world acoustic records for public engagement, are discussed further in the online supplementary materials.
TECHNICAL DEVELOPMENT

OF AN OCEAN WORLDS

\section{PASSIVE ACOUSTIC SYSTEM}

We think autonomous hydrophone systems that could be used to explore an ocean world already exist. Passive acoustic monitoring (PAM) systems have been installed on an ocean glider and a profiler float (Matsumoto et al., 2011, 2013), successfully recording, detecting, and classifying deep-ocean geophysical and biological sounds. These instruments are useful analogs for what can be achieved on an ocean world in that they operate in remote, inhospitable environments, are very low-power, and perform without human intervention for long periods. These oceanographic mobile platforms also have minimal downlink bandwidth through which to communicate (via Iridium satellite connection).

The hydrophone technology will need to be tested for the rigors of spaceflight, including materials selected for outgassing concerns, extreme temperatures that will be encountered on outer solar system worlds, and shock and vibration conditions during launch (Table 2). The signal processing electronics are not a difficult design problem, but re-casting the autonomous processing electronics into a system that can endure spaceflight, yet retain the minimal power requirements, is critical. Lastly, the signal identification and classification algorithms needed to reduce the transmitted data sizes to meet downlink requirements for an ocean world exploration mission will be derived from similar concepts already used on mobile marine instruments and platforms on Earth. However, the bandwidth of potential signals of interest may be much wider on outer solar system worlds than it is on Earth (all signals are of interest, both geophysical and biological), and signal ranking system would need to be developed.

Ocean World Hydrophone Overview The three developmental components of an ocean worlds passive acoustic technology project are (1) the hydrophone element, (2) signal-processing electronics, 
and (3) signal identification/classification algorithms. The hydrophone and processing electronics could be built together to enable laboratory testing, and hydrophone designs (for Titan, Europa, and Enceladus), electronics, and identification/classification algorithms could be tested in sea trials on Earth. It is assumed that the signal-processing electronics would be held within the hull of the exploration vehicle to maintain a relatively hospitable temperature (e.g., $-40^{\circ} \mathrm{C}$ or above). This separation between the hydrophone sensor and instrument electronics will not be a problem (e.g., due to signal attenuation) for distances up to $\sim 10 \mathrm{~m}$, which is significantly longer than expected for the size of an ocean world exploration vehicle.

Table 2 shows the estimated requirements for the successful performance of a hydrophone meeting our planetary exploration science goals. This exercise serves to show the different thermal environments that the Titan hydrophone must survive. The temperature requirements are based on the expected ambient conditions in the target body's seas, as well as survival requirements expected during deep-space cruise conditions and NASA's planetary protection thermal-sterilization requirements to prevent contamination. The pressure limits are set by the expected depth of the seas. We assumed the vehicle would remain within the top $10 \mathrm{~km}$ of the Europa or Enceladus oceans but may be at the floor of a Titan sea. The $\mathrm{pH}$ requirements were set to account for potentially inhospitable acidic seas (Towner et al., 2006). The hydrophone sensitivity floor was set to enable detection of acoustic signals from a hydrothermal vent sound source at distances of tens to hundreds of meters, assuming terrestrial-ocean spherical spreading and transmission loss. We assumed an ambient noise floor similar to a quiet ice-covered sea (as in Antarctica; Dziak et al., 2015) and a hydrothermal vent acoustic source level (Figure 4; Crone et al., 2006) caused by cavitation due to turbulent fluid flow through a vent chimney. The high signal saturation level is required to enable a high dynamic range because of the uncertainty in the noise spectral level and the likelihood of a highly red spectral character.

Lastly, the high sample rate for both Europa/Enceladus and Titan hydrophones (0.01-40 kHz; Table 2) were selected to include a wide variety of potential signal sources. Types and frequencies of these sources as observed on Earth range from high-temperature hydrothermal vent systems $(\leq 200 \mathrm{~Hz})$ to seismo-acoustic volcano and cryogenic signals $(10-500 \mathrm{~Hz})$, seafloor bubble streams ( $\max \leq 45 \mathrm{kHz}$ ), and potential bioacoustics signals, which could be broadband and high frequency as well (10 Hz to tens of kilohertz). A $40 \mathrm{kHz}$ sample rate would create $2.56 \mathrm{~TB}$ of acoustic data over a one-year recording period, which should be an easily manageable data volume, given current commercially available solid-state-drive storage capacities. However, given that the data will be processed in real time for transmission of detected events back to Earth, there really is no need to retain the data onboard the vehicle, enabling use of lower-capacity, lower-power data storage systems. This data archive will also only be needed for the duration of the vehicle's mission on an outer world, as the data will be used by embedded identification and classification algorithms that will parameterize signals of value for transmission back to Earth (see following sections).

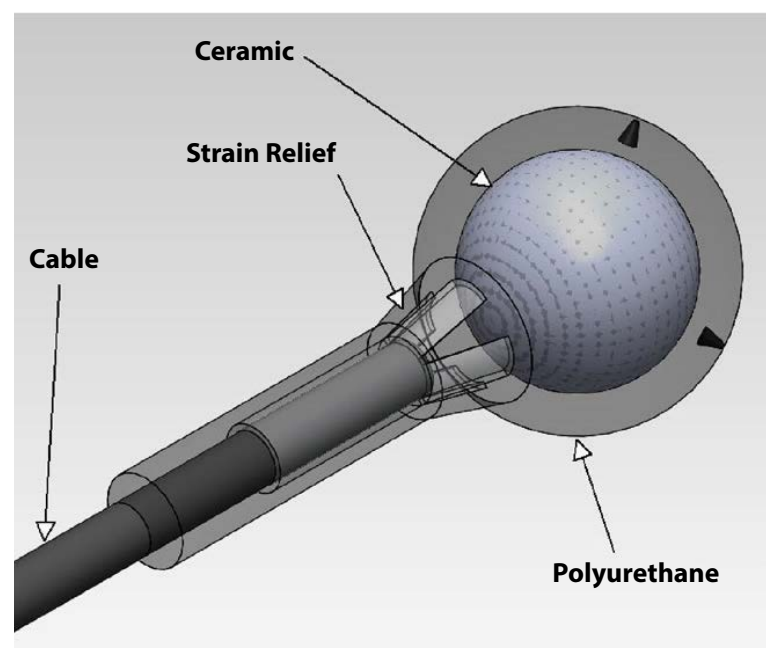

\section{Hydrophone Requirements}

for Europa/Enceladus

The relatively benign thermal environment (by outer solar system standards) needed for a Europa/Enceladus hydrophone suggests that a standard commercial product may be suitable. Deepwater, omnidirectional transducers are available from several manufacturers (e.g., Teledyne Reson; Figure 5). Many commercial entities that supply hydrophones for oceanographic applications are already familiar with designing transducers capable of thermal sterilization for medical applications. Whether the materials encasing the hydrophone sensor head are compatible with spaceflight will still need to be examined. Also, the stringent NASA planetary protection requirements for Europa and Enceladus missions mean that outgassing and cold performance of the materials chosen need to be considered, as well as the material's ability to survive thermal sterilization. Outgassing characteristics are driven by the requirement to not contaminate other instruments during spaceflight while in a hard vacuum for several years. The shock and vibration requirements needed for spaceflight may necessitate some redesign of an off-theshelf transducer head. However, piezoelectric transducers are often robust where mechanical shock and vibration are unlikely to damage the device.
FIGURE 5. Schematic of an example hydrophone for spaceflight development. Shock and vibration requirements for space flight may necessitate transducer redesign; however, piezoelectric transducers are often robust when subjected mechanical shock. As transducers are capable of both receiving and emitting sound, it is possible this sensor could also serve engineering roles on a future vehicle as an active sonar, or possibly even as an acoustic modem for a communication network composed of nearby seafloor sensors. 
Hydrophone Requirements for Titan Meeting hydrophone design requirements for Europa/Enceladus would be the first step in adapting a hydrophone for survival and performance under the environmental conditions needed for Titan. Principally, this would involve increasing the cold tolerance of the hydrophone from that acceptable for Europa/ Enceladus down to $-183^{\circ} \mathrm{C}$ for Titan's surface temperatures. Also, depending on how the platform is delivered, for example, in slow parachute descent, the vehicle could experience the Titan tropopause minimum temperature of $-203^{\circ} \mathrm{C}$. To ensure continued performance at these very low temperatures would take further redesign of the mechanical structures of the hydrophone and careful selection of materials. Simpler narrowband transducers have been sent to Titan (e.g., Towner et al., 2006), and Arvelo and Lorenz (2013) successfully tested another narrowband transducer to liquid nitrogen $\left(\mathrm{LN}_{2}\right)$ temperatures of $77 \mathrm{~K}$, colder than Titan's 90-94 K surface temperatures. Thus, it appears that a material solution for a broadband sensor would be available. The acoustic impedance of Titan's seas is different than in Earth's ocean, of course, but not so dramatically that it is expected to be a driver in the redesign. The difference in the fluid properties could be accommodated to optimize the hydrophone for Titan's ethane/methane seas. Lastly, an important simplification exists for Titan instrumentation, in that the ocean is electrically insulating. Many of the reliability issues that confound terrestrial electronics in marine applications are obviated, and electrical conductors can be exposed without issue.

One approach to laboratory testing a Titan hydrophone would be to immerse the hydrophone in a Dewar of $\mathrm{LN}_{2}$, similar to the approach used by Arvelo and Lorenz (2013). The $\mathrm{LN}_{2}$ temperature would slightly exceed the extremely cold surface temperature of Titan, and $\mathrm{LN}_{2}$ differs from seawater in acoustic impedance. The biggest challenge in designing a Titan hydrophone is the extreme temperature, so this approach would constitute a strong test of the design presented.

\section{Signal Processing Electronics}

Passive acoustic recording and processing electronics that have been built for deep-sea mobile platforms (Matsumoto et al., 2011, 2013) would need to be adapted to enable them to survive spaceflight and yet retain the high performance and extremely low power requirements that an ocean worlds exploration mission would require. Here, we address two aspects of this adaptation. The first is whether the system architecture for terrestrial deep-sea instrumentation is compatible with deep-space flight, typically meaning that it is radiation-hardened against cosmic ray hits. Until recently, this would have meant a redesign of the architecture (now using ARM microprocessors and digital signal processors, or DSPs). However, in the last year, likely because of pressure from the CubeSat community, radiation-hardened ARM processors are now available (e.g., Vorago Technologies), and radiation-hardened DSPs have also existed for somewhat longer. Thus, adapting the existing terrestrial signal processing electronics will not be a difficult process.

A second area of significant concern in designing signal processing electronics for making acoustic recordings in any new environment is to properly anticipate the different ambient noise levels that will occur in the various outer-world environments and how the levels will differ from Earth's ocean. Models of the expected noise levels on the ocean and surface sea worlds (Arvelo and Lorenz, 2013) allow us to anticipate to some extent ocean and sea noise acoustic environments on Europa and Titan. In our view, it will be critical to develop an amplifier with automatic gain control (AGC) to avoid saturating our analog-to-digital converters (ADC) if the noise environment is vastly different than the predictions. Adjustable gain amplifiers can be controlled by the processor to avoid signal saturation, which will make the best use of the $148 \mathrm{~dB}$ dynamic range of the 24-bit ADC. As an example of the wide range of noise levels possible, Figure 6 shows the observed noise spectra in a variety of conditions in Earth's ocean, where ambient noise from natural sources can range in power spectral density by $\sim 100 \mathrm{~dB}$ re $\mu \mathrm{Pa}^{2} / \mathrm{Hz}$.

\section{Signal Identification and}

\section{Classification Algorithms}

Acoustic signal detection and classification algorithms are used widely in oceanographic research to automate evaluation of long-term acoustic data sets for geophysical and biological signals of interest in the ocean (for a review, see Mellinger et al., 2016). Over the last decade, acoustic near-real-time applications have become important tools in the detection of marine mammal vocalizations for use in assessing their population sizes and geographic distributions (e.g., Klinck et al., 2012). Significant advancements have been made in the development and operation of stationary and mobile autonomous systems that screen the underwater soundscape continuously for signals of interest and report the occurrence of such signals back to shore, commonly through an Iridium satellite link (Klinck et al., 2012; Matsumoto et al., 2013; Baumgartner et al., 2019). The software implemented on these systems is typically multilayered. In the initial stage, a detection algorithm flags general sounds of interest. First-stage detectors are often very simple in nature (e.g., band-limited energy detector) and generate a significant amount of false positive detections; however, they are very efficient energy-wise, with a low-computational load (Mellinger et al., 2016) and can even be analog in nature (e.g., analog filter banks). If acoustic signals of interest are detected, they are parsed into a second-stage classifier for verification and identification (Klinck and Mellinger, 2011). As the occurrence ratio of interesting signals versus noise is usually heavily skewed toward noise, this helps to keep the overall power consumption low. 
This is a key feature as these systems are always power limited, with a finite battery storage capacity.

\section{Single Versus Multiple Sensors}

In our experience, it is very common to detect signals (broadband and single tone) that are not easily classified as geophysical, meteorological, cryogenic, or biological and that may have characteristics of all three. One aspect that is of tremendous aid in evaluating the source mechanism of a given signal is to determine the location of the source (e.g., seafloor or water column, fault line or seamount, ice edge or open ocean). Having the ability to estimate the location, or at least the direction, of the acoustic source will greatly aid in determining the nature of the source. To achieve this capability may require having multiple sensors (separated by a short distance proportional to the wavelength of signals to be recorded), or employing a single vector hydrophone to derive signal directionality. Indeed, employing vector sensors for directionality may help differentiate between noise generated by the lander and actual environmental signals. However, because of design complications associated with a vector sensor (added weight, need for a compass, and three-axis accelerometer), it would still seem best to use either a single hydrophone sensor element or potentially employ two to three hydrophones on the lander. Further detailed discussions on (1) signal identification and classification algorithms, (2) data transmission considerations from Titan to Earth, and (3) planetary protection tests (spaceflight shock and vibration) needed for a hydrophone system to be included on a Europa/Enceladus lander or Titan saildrone are presented in the online supplementary material.

\section{SUMMARY}

We presented an overview of hydrophone sensor systems and signal processing techniques developed for underwater acoustic research on Earth and described how these sound sensing technologies might be used to explore ocean and surface sea worlds in the outer solar system. Passive acoustic recording and processing electronics that have been built for deep-sea mobile platforms (Matsumoto et al., 2011, 2013) could be adapted to survive spaceflight and yet retain the high performance and extremely low power requirements of an ocean worlds exploration mission. The hydrophone, microprocessor, and system electronics will also need to withstand the thermal sterilization required under NASA's planetary protection requirements. Both of these hydrophone designs could be tested in deep-ocean conditions on Earth by lowering the instrument to $1,300 \mathrm{~m}$, equivalent to $\sim 10 \mathrm{~km}$ depth on Europa and $\sim 120 \mathrm{~km}$ depth on Enceladus, sufficient for exploration beneath the ice shell on these worlds. The Titan hydrophone would need to be tested in an $\mathrm{LN}_{2}$ tank, a proxy for the thermal conditions of Titan's seas.

The acoustic monitoring system proposed here could be a candidate for a Europa or Enceladus mission that would seek a means to enter fluid oceans, via either cracks or melting through the ice shell. The Europa/Enceladus oceans should be dominated by cryogenic sounds from the ice shell and geophysical sound sources generated in the subocean lithic crust. An under-ice hydrophone should have a much better chance of detecting acoustic signals from a subocean volcano-tectonic source than seismometers on the ice shell surface. However, passive acoustic systems might best be used for a near-term mission to a Titan surface sea. The hydrophone sensor could be deployed on a tether, or possibly use a winch system to deploy a hydrophone array some distance from a vehicle. Previous studies (e.g., Arvelo and Lorenz, 2013; Lopes et al., 2013) assert that Titan should have a dynamic undersea soundscape where signals from cryo-volcanic activity, and harmonic tones from fluid flow at hydrothermal vent chimneys, are all potentially detectable sources of sound.

An accepted possible scenario for life to thrive on worlds like Europa, Enceladus, and Titan is at hydrothermal fluid springs near seafloor volcanic centers or, as may be the case for Titan, associated with

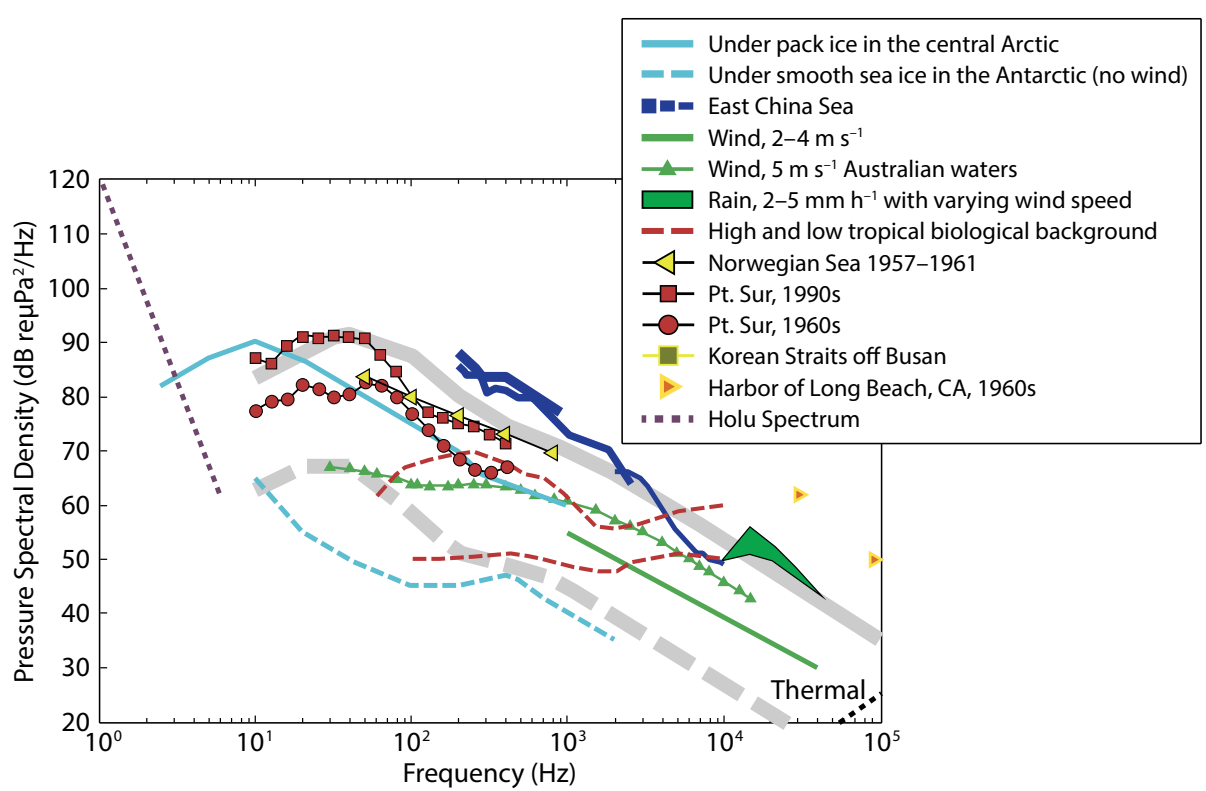

FIGURE 6. Diagram showing various noise spectra from different conditions in Earth's ocean, ranging from under sea ice (quietest) to high sea states and busy shipping channels (noisiest). The red dashed lines indicate high and low biological background noise levels. Predictions of these noise levels on the ocean worlds are preliminary at best, and combined with the variability that may occur from place to place, it is critical that a passive acoustic recording system can dynamically alter gain settings. After Dahl et al. (2007) 
cold seeps in the shallow seas. These hot/ cold springs could provide the energy source for chemosynthetic ecosystems to develop. Thus, one method to find life would be to detect and locate these volcanic centers or cold seep sources using their geophysical acoustic signals, then directly sample the fluids to search for chemical evidence of life. Alternatively, it is not out of the realm of possibility that if extant macro-life has evolved on these ocean worlds, it may also produce some sort of detectable acoustic signal.

Our goal was to describe methods on how to design and protect a passive acoustic monitoring and signal detection system for the rigors of spaceflight and planetary exploration. We think it may be achievable with the methods outlined here. @

\section{ONLINE SUPPLEMENTARY MATERIALS}

The supplementary materials are available online at https://doi.org/10.5670/oceanog.2020.221.

\section{REFERENCES}

Arvelo, J., and R. Lorenz. 2013. Plumbing the depths of Ligeia: Considerations for depth sounding in Titan's hydrocarbon seas. Journal of the Acoustical Society of America 134:4335, https://doi.org/ 10.1121/1.4824908.

Au, W.W.L., A.N. Popper, and R.R. Fay. 2000

Hearing by Whales and Dolphins. Springer-Verlag, New York, 485 pp.

Baumgartner, M.F., J. Bonnell, S.M. Van Parijs, P.J. Corkeron, C. Hotchkin, K. Ball, L-P. Pelletier, J. Partan, D. Peters, J. Kemp, and others. 2019. Persistent near real-time passive acoustic monitoring for baleen whales from a moored buoy: System description and evaluation. Methods in Ecology and Evolution 10(9):1,476-1,489, https://doi.org/ 10.1111/2041-210X.13244.

Bohnenstiehl, D.R., A. Lillis, and D.B. Eggleston. 2016. The curious acoustic behavior of estuarine snapping shrimp: Temporal patterns of snapping shrimp sound in sub-tidal oyster reef habitat. PLOS ONE 11(1):e0143691, https://doi.org/10.1371/ journal.pone.0143691.

Cadek, O., G. Tobie, T. Van Hoolst, M. Massé, G. Choblet, A. Lefévre, G. Mitri, R.-M. Baland, M. Behounková, O. Bourgeois, and A. Trinh. 2016. Enceladus's internal ocean and ice shell constrained from Cassini gravity, shape, and libration data. Geophysical Research Letters 42(11):5,653-5,660, https://doi.org/10.1002/ 2016GL068634.

Caplan-Auerbach, J., R.P. Dziak, J. Haxel, D.R. Bohnenstiehl, and C. Garcia. 2017. Explosive processes during the 2015 eruption of Axial Seamount, as recorded by seafloor hydrophones. Geochemistry, Geophysics, Geosystems 18(4):1,761-1,774, https://doi.org/ 10.1002/2016GC006734.

Choblet, G., G. Tobie, C. Sotin, M. Behounková, O. Cadek, F. Postberg, and O. Soucek. 2017. Powering prolonged hydrothermal activity inside Enceladus. Nature Astronomy 1:841-847, https://doi.org/10.1038/s41550-017-0289-8.
Chyba, C.F., and C.B. Phillips. 2001. Possible ecosystems and the search for life on Europa. Proceedings of the National Academy of Sciences of the United States of America 98(3):801-804, https://doi.org/10.1073/pnas.98.3.801.

COLDTech. 2016. Concepts for Ocean Life Detection, NASA Research Announcement in Space and Earth Sciences, ROSES-2016, https://nspires.nasaprs.com.

Cordier, D., O. Mousis, J.I. Lunine, P. Lavvas, and V. Vuitton. 2009. An estimate of the chemical composition of Titan's lakes. The Astrophysical Journal Letters 707(2):L128-L131, https://doi.org/ 10.1088/0004-637X/707/2/L128.

Cordier, D., F. Garcia-Sanchez, D.N. Justo-Garcia, and G. Liger-Belair. 2017. Bubble streams in Titan's seas as a product of liquid $\mathrm{N}_{2}+\mathrm{CH}_{4}+\mathrm{C}_{2} \mathrm{H}_{6}$ cryogenic mixture. Nature Astronomy 1:0102, https://doi.org/ 10.1038/s41550-017-0102.

Crone, T.J., W.S.D. Wilcock, A.H. Barclay, J.D. Parsons. 2006. The sound generated by mid-ocean ridge black smoker hydrothermal vents. PLOS ONE 1(1):e133, https://doi.org/10.1371/journal. pone.0000133.

Dahl, P.H., J.H. Miller, D.H. Cato, and R.K. Andrew. 2007. Underwater ambient noise. Pp. 23-33 in Acoustics Today, January 2007.

Dougherty, M.K., K.K. Khurana, F.M. Neubauer, C.T. Russell, J. Saur, J.S. Leisner, and M.E. Burton. 2006. Identification of a dynamic atmosphere at Enceladus with the Cassini Magnetometer. Science 311(5766):1,406-1,409, https://doi.org/ 10.1126/science.1120985.

Dziak, R.P., J.H. Haxel, D.R. Bohnensteihl, W.W. Chadwick Jr., S.L. Nooner, M.J. Fowler, H. Matsumoto, and D.A. Butterfield. 2012. Seismic precursors and magma ascent before the April 2011 eruption at Axial Seamount. Nature Geoscience 5:478-482, https://doi.org/10.1038/ ngeo1490.

Dziak, R.P., D.R. Bohnenstiehl, K.M. Stafford, H. Matsumoto, M. Park, W.S. Lee. M.J. Fowler, T.-K. Lau, J.H. Haxel, and D.K. Mellinger. 2015. Sources and levels of ambient ocean sound near the Antarctic Peninsula. PLOS ONE 10(4):e0123425, https://doi.org/10.1371/journal.pone.0123425.

Dziak, R.P., J.H. Haxel, H. Matsumoto, T.-K. Lau, S. Heimlich, S. Nieukirk, D. K. Mellinger, J. Osse, C. Meinig, N. Delich, and S. Stalin. 2017. Ambient sound at Challenger Deep, Mariana Trench. Oceanography 30(2):186-197, https://doi.org/ 10.5670/oceanog.2017.240.

Dziak, R.P., H. Matsumoto, R.W. Embley, S.G. Merle, T.-K. Lau, T. Baumberger, S.R. Hammond, and N. Rainault. 2018. Passive acoustic records of seafloor methane bubble streams on the Oregon continental margin. Deep Sea Research Part // 150:210-217, https://doi.org/10.1016/j.dsr2. 2018.04.001.

Erbe, C., and A.R. King. 2008. Automatic detection of marine mammals using information entropy. Journal of the Acoustical Society of America 124:2,833-2,840, https://doi.org/10.1121 1.2982368.

Fregosi, S., D.V. Harris, H. Matsumoto, D.K. Mellinger, C. Negretti, D.J. Moretti, S.W. Martin, B. Matsuyama, P.J. Dugan, and H. Klinck. 2020. Comparison of fin whale $20 \mathrm{~Hz}$ call detections by deep-water mobile autonomous and stationary recorders. Journal of the Acoustical Society of America 147:961, https://doi.org/10.1121/10.0000617.

Hartwig, J.W., A. Colozza, R.D. Lorenz, S. Oleson, G. Landis, P. Schmitz, M. Paul, and J. Walsh. 2016. Exploring the depths of Kraken Mare-Power, thermal analysis, and ballast control for the Saturn Titan submarine. Cryogenics 74:31-46, https://doi.org/ 10.1016/j.cryogenics.2015.09.009.

Hayes, A.G. 2016. The lakes and seas of Titan. Annual Review of Earth and Planetary Science 44:57-83, https://doi.org/10.1146/ annurev-earth-060115-012247.
Hemingway, D., F. Nimmo, H. Zebkar, and L. less. 2013. A rigid and weathered ice shell on Titan. Science 500(7464):550-442, https://doi.org/ 10.1038/nature12400.

Hood, J., D.G. Flogeras, and J.A. Theriault. 2016. Improved passive acoustic band-limited energy detection for cetaceans. Applied Acoustics 106:36-41, https://doi.org/10.1016/ j.apacoust.2015.12.011.

Hofgartner, J.D., A.G. Hayes, J.I. Lunine, H. Zebker, B.W. Stiles, C. Sotin, J.W. Barnes, E.P. Turtle, K.H. Baines, R.H. Brown, and others. 2014. Transient features in a Titan sea. Nature Geoscience 7:493-496, https://doi.org/10.1038/ ngeo2190.

less, L., R.A. Jacobson, M. Ducci, D.J. Stevenson, J.I. Lunine, J.W. Armstrong, S.W. Asmar, P. Racioppa, N.J. Rappaport, and P. Tortora. 2012. The tides of Titan. Science 337(6093):457-459, https://doi.org/ 10.1126/science.1219631.

Johnson, H.P., U.K. Miller, M.S. Salmi, and

E.A. Solomon. 2015. Analysis of bubble plume distributions to evaluate methane hydrate decomposition on the continental slope. Geochemistry, Geophysics, Geosystems 16:3,825-3,839, https://doi.org/10.1002/2015GC005955.

Keenan, R.E., and L.R.L. Merriam. 1991. Arctic abyssal $T$ phases: Coupling seismic energy to the ocean sound channel via under ice scattering. Journal of the Acoustical Society of America 89:128, https://doi.org/10.1121/1.400648.

Klein, F.W., R.Y. Koyanagi, J.S. Nakata, and W.R. Tanigawa. 1987. The seismicity of Kilauea's magma system. Pp. 1,019-1,186 in Volcanism in Hawai'i: Papers to Commemorate the 75th Anniversary of the Founding of the Hawaiian Volcano Observatory. R.W. Decker, T.L. Wright, and P.H. Stauffer, eds, US Geological Survey Professional Paper 1350.

Klinck, H., and D.K. Mellinger. 2011. The energy ratio mapping algorithm: $A$ tool to improve the energy-based detection of odontocyte echolocation clicks. Journal of the Acoustical Society of America 129:1,807-1,812, https://doi.org/10.1121/ 1.3531924.

Klinck, H., D.K. Mellinger, K. Klinck, N.M. Bogue, J.C. Luby, W.A. Jump, G.B. Shilling, T. Litchendorf, A.S. Wood, G.S. Schorr, and R.W. Baird. 2012. Near-real-time acoustic monitoring of beaked whales and other cetaceans using a Seaglider. PlosONE 7(5):e36128, https://doi.org/10.1371/journal. pone.0036128.

Lee, S., M. Zanolin, A.M. Thode, R.T. Pappalardo, and N.C. Makris. 2003. Probing Europa's interior with natural sound sources. Icarus 165:144-167, https://doi.org/10.1016/S0019-1035(03)00150-7.

Leifer, I., and D. Tang. 2007. The acoustic signature of marine seep bubbles. Journal of the Acoustical Society of America 121(1), https://doi.org/10.1121/ 1.2401227.

Leighton, T.G., P.R. White, and D.C. Finfer. 2013. The opportunities and challenges in the use of extraterrestrial acoustics in the exploration of the oceans of ice planetary bodies. Earth, Moon, and Planets 109:91116, https://doi.org/10.1007/ s11038-012-9399-6.

Lopes, R.M.C., R.L. Kirk, K.L. Mitchell, A. LeGall, J.W. Barnes, A. Hayes, J. Kargel, L. Wye, J. Radebaugh, E.R. Stofan, and others. 2013. Cryovolcanism on Titan: New results from Cassini RADAR and VIMS. Journal of Geophysical Research 118:416-435, https://doi.org/10.1002/ jgre.20062.

Lorenz, R.D., T. Tokano, and C. Newman. 2012. Winds and tides of Ligeia Mare, with application to the drift of the proposed TiME (Titan Mare Explorer) capsule. Planetary and Space Science 60:72-85, https://doi.org/10.1016/j.pss.2010.12.009.

Lorenz, R.D. 2014. The flushing of Ligeia: Composition variations across Titan's seas in a simple hydrological model. Geophysical Research Letters 41(16):5,764-5,770, https://doi.org/ 10.1002/2014GL061133. 
Lorenz, R.D., and J.L. Mann. 2015. Seakeeping on Ligeia Mare: Dynamic response of a floating capsule to waves on the hydrocarbon seas of Saturn's moon Titan. John's Hopkins/APL Technical Digest 33(2), https://www.jhuapl.edu/Content/ techdigest/pdf/V33-N02/33-02-Lorenz.pdf.

Lorenz, R.D., S.R. Oleson, A.J. Colozza, R. Jones, T. Packard, J. Hartwig, J.M. Newman, J.Z. Gyekenyesi, P. Schmitz, and J. Walsh. 2018 Exploring Titan's cryogenic hydrocarbon seas with boat deployed expendable dropsondes. Advances in Space Research 62(4):912-920, https://doi.org/ 10.1016/j.asr.2018.05.030.

Lunine, J.I. 2017. Ocean worlds exploration. Acta Astronautica 131:123-130, https://doi.org/10.1016/ j.actaastro.2016.11.017.

Ma, B.B., and J.A. Nystuen. 2005. Passive acoustic detection and measurement of rainfall at sea. Journal of Atmospheric and Oceanic Technology 22:1,225-1,248, https://doi.org/10.1175/ JTECH1773.1.

MacAyeal, D.R., E.A. Okal, R. Aster, and J.N. Bassis 2008. Seismic and hydroacoustic tremor generated by colliding icebergs. Journal of Geophysical Research 113(F3), https://doi.org/ 10.1029/2008jf001005.

Mastrogiuseppe, M., V. Poggiali, A. Hayes, R. Lorenz, J. Lunine, G. Picardi, R. Seu, E. Flamini, G. Mitri, P. Paillou, and H. Zebker. 2014. The bathymetry of a Titan sea. Geophysical Research Letters 41:1,432-1,437, https://doi.org/10.1002/ 2013 GL058618.

Mastrogiuseppe, M., V. Poggiali, A.G. Hayes, J.I. Lunine, R. Seu, G. Mitri, and R.D. Lorenz. 2019. Deep and methane-rich lakes on Titan. Nature Astronomy 3:535-542, https://doi.org/10.1038/ s41550-019-0714-2.

Matsumoto, H., D.R. Bohnenstiehl, J.H. Haxel, R.P. Dziak, and R.W. Embley. 2011. Mapping the sound field of an erupting submarine volcano using an acoustic glider. Journal of the Acoustical Society of America 129(3), https://doi.org/10.1121/1.3547720.

Matsumoto, H., C. Jones, H. Klinck, D.K. Mellinger R.P. Dziak, and C. Meinig. 2013. Tracking beaked whales with a passive acoustic profiler float. Journal of the Acoustical Society of America 133:731-740, https://doi.org/10.1121/ 1.4773260.

McCarthy, C., K.L. Craft, C.R. German, M.V. Jakuba, R.D. Lorenz, G.W. Patterson, and A. Rhoden. 2019 Europa STI: Exploring communication techniques and strategies for sending signals through the Ice (STI) for an Ice-Ocean probe. Ocean Worlds 2019, May 21-22, Columbia, Maryland, Contribution No. 2168 (extended abstract).

McCord, T.B., and G.B. Hansen. 1998. Salts on Europa's surface detected by Galileo's near infrared mapping spectrometer. Science 280(5367):1,242-1,245, https://doi.org/ 10.1126/science. 280.5367 .1242

McGrath, M.A., C.J. Hansen, and A.R. Hendrix. 2009. Observations of Europa's tenuous atmosphere. Pp. 485-506 in Europa. R.T. Pappalardo, W.B. McKinnon, and K. Khurana, eds, University of Arizona Press.

Meinig, C., E.F. Burger, N. Cohen, E.D. Cokelet, M.F. Cronin, J.N. Cross, S. de Halleux, R. Jenkins, A.T. Jessup, C.W. Mordy, and others. 2019. Publicprivate partnerships to advance regional ocean observing capabilities: A saildrone and NOAA PMEL case study and future considerations to expand to global scale observing. Frontiers in Marine Science 6:448, https://doi.org/10.3389/, fmars.2019.00448.

Mellinger, D.K., M.A. Roch, E.M. Nosal, and H. Klinck. 2016. Signal Processing. Pp. 359-411 in Listening in the Ocean. W.W.L. Au and M.O. Lammers, eds, Springer, New York.

Melosh, H.J., A.G. Ekholm, A.P. Showman, and R.D. Lorenz. 2004. The temperature of Europa's subsurface water ocean. Icarus 168:498-502, https://doi.org/10.1016/j.icarus.2003.11.026.
Merchant, N.D., T.R. Barton, P.M. Thompson, and E. Pirotta. 2013. Spectral probability density as a tool for ambient noise analysis. Journal of the Acoustical Society of America 133:EL262, https://doi.org/10.1121/1.4794934.

Mitri, G., A.P. Showman, J.I. Lunine, and R.D. Lorenz. 2007. Hydrocarbon lakes on Titan. Icarus 186(2):385-394, https://doi.org/10.1016/ j.icarus.2006.09.004.

Niemann, H.B., S.K. Atreya, S.J. Bauer, G.R. Carignan, J.E. Demick, R.L. Frost, D. Gautier, J.A. Haberman, D.N. Harpold, D.M. Hunten, and others. 2005. The abundances of constituents of Titan's atmosphere from the GCMS instrument on the Huygens probe. Nature 438(7069):779-784, https://doi.org/10.1038/ nature04122.

Nimmo, F., B. Giese, and R.T. Pappalardo. 2003. Estimates of Europa's ice shell thickness from elastically supported topography. Geophysical Research Letters 30(5), https://doi.org/10.1029/ 2002 GL016660.

Nimmo, F., and R.T. Pappalardo. 2016. Ocean worlds in the outer solar system. Journal of Geophysical Research 121(8):1,378-1,399, https://doi.org/10.1002/ 2016JE005081.

Panning, M., V. Lekic, M. Manga, F. Cammarano, and B. Romanowicz. 2006. Long-period seismology on Europa: Part 2. Predicted seismic response. Journal of Geophysical Research 111(E12), https://doi.org/ 10.1029/2006JE002712.

Pappalardo, R.T., M.J.S. Belton, H.H. Breneman, M.H. Carr, C.R. Chapman, G.C. Collins, T. Denk S. Fagents, P.E. Geissler, B. Giese, and others. 1999 Does Europa have a subsurface ocean? Evaluation of the geological evidence. Journal of Geophysical Research 104:24,015-24,055, https://doi.org/ 10.1029/1998JE000628.

Podolskiy, E.A., and F. Walter. 2016. Cryoseismology. Review of Geophysics 54:708-758, https://doi.org/ 10.1002/2016RG000526.

Postberg, F., N. Khawaja, B. Abel, G. Choblet, C.R. Glein, M.S. Gudipati, B.L. Henderson, H.-W. Hsu, S. Kempf, F. Klenner, and others. 2018. Macromolecular organic compounds from the depths of Enceladus. Nature 558:564-568, https://doi.org/10.1038/s41586-018-0246-4.

Royer, J.-Y., R. Chateau, R.P. Dziak, and D.R. Bohnenstiehl. 2015. Seafloor seismicity, Antarctic ice-sounds, cetacean vocalizations and long-term ambient sound in the Indian Ocean basin. Geophysical Journal International 202:748-762, https://doi.org/ 10.1093/gji/ggv178.

Schmitz, W.J. Jr., and M.S. McCartney. 1993. On the North Atlantic Circulation Reviews of Geophysics 31(1):29-49, https://doi.org/10.1029/ 92RG02583.

Schubert, G., J.D. Anderson, T. Spohn, and W.B. McKinnon. 2004. Pp. 263-280 in Jupiter: The Planet, Satellites and Magnetosphere. F. Bagenal, T.E. Dowling, and W.B. McKinnon, eds, Cambridge University Press.

Smith-Konter, B., and R.T. Pappalardo. 2008. Tidally driven stress accumulation and shear failure of Enceladus's tiger stripes. Icarus 198:435-451, https://doi.org/10.1016/j.icarus.2008.07.005.

Stofan, E., C. Elachi, J.I. Lunine, R.D. Lorenz, B. Stiles, K.L. Mitchell. S. Ostro, L. Soderblom, C. Wood, H. Zebkar, and others. 2007. The lakes of Titan. Nature 445:61-64, https://doi.org/10.1038/ nature05438.

Stofan, E.C., R. Lorenz, J. Lunine, E.B. Bierhaus, B. Clark, P.R. Mahaffy, and M. Ravine. 2013. TiMEThe Titan Mare Explorer. 2013 IEEE Aerospace Conference, March 2-9, 2013, Big Sky, Montana, https://doi.org/10.1109/AERO.2013.6497165.

Talandier, J., O. Hyvernaud, E.A. Okal, and P.F. Piserchia. 2002. Long range detection of hydroacoustic signals from large icebergs in the Ross Sea, Antarctica. Earth and Planetary Science Letters 203:519-534, https://doi.org/10.1016/ s0012-821x(02)00867-1.
Towner, M.C., J.R.C. Garry, R.D. Lorenz, A. Hagermann, B. Hathi, H. Svedhem, B.C. Clark, M.R. Leese, and J.C. Zarnecki. 2006. Physical properties of Titan's surface at the Huygens landing site from the Surface Science Package Acoustic Properties sensor (API-S). Icarus 185:457-465, https://doi.org/ 10.1016/j.icarus.2006.07.013.

Vance, S., J. Harnmeijer, J. Kimura, H. Hussmna, B. deMartin, and J.M. Brown. 2007. Hydrothermal systems in small ocean planets. Astrobiology 7(6), https://doi.org/10.1089/ast.2007.0075.

Vance, S.D., M.P. Panning, S. Stähler, F. Cammarana, B.G. Bills, G. Tobie, S. Kamata, S. Kedar, C. Sotin, W.T. Pike, and others. 2017. Geophysical investigations of habitability in ice-covered ocean worlds. Journal of Geophysical Research 123(1):180-205, https://doi.org/10.1002/2017JE005341.

Vance, S.D., S. Kedar, M.P. Panning, S.C. Stähler, B.G. Bills, R.D. Lorenz, H.-H. Huang, W.T. Pike, J.C. Castillo, P. Lognonné, and others. 2018. Vital signs: Seismology of icy ocean worlds. Astrobiology 18(1), https://doi.org/10.1089/ ast.2016.1612.

\section{ACKNOWLEDGMENTS}

The authors wish to thank the editor and two anonymous reviewers for their very helpful comments. Thanks also to D. Butterfield for perspectives on the oxygen requirements of chemosynthetic life. The research in this paper was sponsored by the NOAA/ Pacific Marine Environmental Laboratory, PMEL paper contribution number 5086. All data are available from the authors upon request, without undue reservation, to any qualified researcher.

\section{AUTHORS}

Robert Dziak (robert.p.dziak@noaa.gov) is

Acoustics Program Manager, NOAA/Pacific Marine Environmental Laboratory (PMEL), Newport, OR, USA Don Banfield is Principal Research Scientist, Cornell Center for Astrophysics and Planetary Science, Cornell University, Ithaca, NY, USA. Ralph Lorenz is Planetary Scientist, Applied Physics Laboratory, Johns Hopkins University, Baltimore, MD, USA. Haruyoshi Matsumoto is Research Associate, Cooperative Institute for Marine Resources Studies, Oregon State University, Newport, OR, USA. Holger Klinck is Director, Center for Conservation Bioacoustics, Cornell Lab of Ornithology, Cornell University, Ithaca, NY, USA. Richard Dissly is Advanced Systems Manager for Solar System Exploration, Ball Aerospace \& Technologies Corporation, Boulder, CO, USA. Christian Meinig is Director, Engineering Development Division, NOAA/PMEL, Seattle, WA, USA. Brian Kahn is Computer Systems Manager, Cooperative Institute for Marine Resources Studies, Oregon State University, Newport, OR, USA

\section{ARTICLE CITATION}

Dziak, R., D. Banfield, R. Lorenz, H. Matsumoto, H. Klinck, R. Dissly, C. Meinig, and B. Kahn. 2020. Deep ocean passive acoustic technologies for exploration of ocean and surface sea worlds in the outer solar system. Oceanography 33(2):144-155, https://doi.org/10.5670/oceanog.2020.221.

\section{COPYRIGHT \& USAGE}

This is an open access article made available under the terms of the Creative Commons Attribution 4.0 International License (https://creativecommons.org/ licenses/by/4.0/), which permits use, sharing, adaptation, distribution, and reproduction in any medium or format as long as users cite the materials appropriately, provide a link to the Creative Commons license, and indicate the changes that were made to the original content. 